The Journal of Vitaminology 7, 67-72 (1961)

\title{
ON THE OXIDATION OF DIHYDROTHIAMINE BY ORGANIC AND INORGANIC OXIDANTS ${ }^{1}$
}

\author{
HISATERU MITSUDA, FUMIO KAWAI AND \\ YOSHITO HASHITANI \\ Laboratory of Nutritional Chemistry, Faculty of Agriculture, \\ Kyoto University, Sakyo, Kyoto \\ (Received October 28, 1960)
}

The DHT ${ }^{2}$ was synthesized first by Karrer and Krishna $(1,2)$ in a crystalline form by reducing thiamine or thiamine-thiazolone with $\mathrm{LiAlH}_{4}$. Subseqently, Iwatsu (3) obtained DHT with a high yield by condensing 2-methyl-4-amino5 -aminomethyl-pyrimidine and $\gamma$-aceto- $\gamma$-mercaptopropyl alcohol with formaldehyde. He reported also the chemical characterization of three types of isomers, i. e., normal, iso- and pseudo-forms.

Since the condition of the synthesis is not too different from a natural, physiological one and DHT in acidic solution is easily oxidized to thiamine by atmospheric oxygen as reported by Hirano et al. (4), Matsukawa and Iwatsu (5) suggested a possibility that the compound might be a precursor of thiamine in its biogenesis.

It has been shown that DHT is oxidized easily in vivo, resulting in an appearance of thiamine-like biological activity in several experiments using microorganisms, root of pisum (6), rice birds (3) and rats (1). In this paper, the fundamental experiments were carried out using inorganic and organic oxidants, in order to characterize the DHT-oxidizing reagent operative in nature.

\section{EXPERIMENTAL}

\section{Methods}

The samples of normal- and pseudo-DHT were synthesized by Iwatsu's method (3). The $\mathrm{R}_{\mathrm{F}}$-value of $\mathrm{DHT}$ was 0.83 and that of thiamine-HCl was 0.41 , using the mixture of isopropanol and $M / 15$ phosphate buffer, $\mathrm{pH} 7.0,(5: 1)$ as a solvent system. The spots showed reddish orange color by Dragendorff reagent. In this experiment, $10.64 \mathrm{mg}$ of DHT was usually dissolved in $50 \mathrm{ml}$ of distilled water without heating and the solution was used as the initial solution.

\footnotetext{
${ }^{1}$ Studies on the Oxidation of Dihydrothiamine. I. The contents of this paper were presented before the 116 th (January 23, 1960) and the 122 th (October 15, 1960) Meetings of the Vitamin B Research Committee and the 12 th Congress of the Vitamin Society of Japan (May 9, 1960).

${ }^{2}$ DHT, dihydrothiamine.
} 
The buffer solutions used were $1 M \mathrm{HCl}$-sodium acetate over the range $\mathrm{pH}$ 1.1 to 5.0 and $0.1 \mathrm{M}$ phosphate over the range $\mathrm{pH} 6.0$ to 7.0 unless otherwise specified. Quantitative estimation of the thiamine produced was performed by the $\mathrm{BrCN}$ method which converts thiamine to thiochrome (7).

\section{Results}

\section{The Oxidation by Dyes}

Methylene blue, 2,6-dichlorophenol indophenol and toluylene blue were used as dyes, and the redox-potential of DHT was estimated from the degree of decolorization of the dyes and from the quantities of the thiamine produced. The results were shown in Tables I and II. DHT was oxidized by the

TABLE I

Decolourization of Dyes

\begin{tabular}{ccccccccccc}
\hline Dye & \multicolumn{3}{c}{ Mb } & \multicolumn{1}{c}{ 2,6-D } \\
$\mathrm{pH}$ & 2.2 & 3.5 & 5.0 & 3.5 & 5.0 & 6.0 & 7.0 & 2.2 & 5.0 \\
$\mathrm{E}_{0}(\mathrm{~V})$ & +0.33 & +0.21 & +0.10 & & +0.36 & +0.29 & +0.22 & +0.39 & +0.22 \\
\hline min & & & & normal-Dihydrothiamine & & & \\
10 & + & + & + & + & + & + & + & + & + \\
30 & + & + & + & \pm & \pm & + & + & + & + \\
60 & + & + & + & - & - & \pm & + & \pm & + \\
120 & + & + & + & - & - & - & + & \pm & + \\
180 & + & + & + & - & - & - & \pm & - & + \\
600 & + & + & + & - & - & - & - & - & + \\
\hline
\end{tabular}

\section{pseudo-Dihydrothiamine}

\begin{tabular}{|c|c|c|c|c|c|c|c|c|c|}
\hline 10 & + & + & + & + & + & $t$ & + & + & + \\
\hline 30 & + & + & + & - & \pm & + & + & \pm & + \\
\hline 60 & + & + & + & - & - & \pm & + & I & + \\
\hline 120 & + & + & + & - & - & I & + & - & + \\
\hline 180 & + & + & + & - & - & - & \pm & - & + \\
\hline 600 & + & + & + & - & - & - & - & - & + \\
\hline
\end{tabular}

$\mathrm{Mb}$, methylene blue; 2,6-D, 2,6-dichlorophenol indophenol, $\mathrm{Tb}$, toluylene blue. + , full color. - , colorless.

Each Thunberg tube contained $1 \mathrm{ml}$ of $2 \times 10^{-4} M$ dye, $1 \mathrm{ml}$ of $4 \times 10^{-4} M$ DHT and $3 \mathrm{ml}$ of buffer solution. The oxidation was perfomed under nitrogen gas at $30^{\circ}$.

dyes having the potentials higher than +0.40 , +0.36 and $+0.23 \mathrm{~V}$ at $\mathrm{pH} 2.2$, 5.0 and 7.0 respectively, nearly in agreement with the results obtained polarographically by Asahi (8). When the concentration of 2,6-dichlorophenol indophenol was increased to 2 to 10 folds excess, the quantities of the thiamine produced remained constant. But a strict stoichiometric correlation between the degree of the decolorization of the dye and the yield of thiamine could not be obtained.

\section{The Aerobic Oxidation in Acidic Solution}

By Hirano's method (4), using active carbon and dilute hydrochloric acid, the amounts of oxygen consumed were estimated by Warburg manometer. 
TABLE II

Formation of Thiamine by Dyes under Anaerobic Condition

\begin{tabular}{|c|c|c|c|c|c|}
\hline \multirow{2}{*}{ Dye } & \multicolumn{2}{|c|}{ Final concentration $(M)$} & \multirow{2}{*}{$\mathrm{pH}$} & \multicolumn{2}{|c|}{ Thiamine formed } \\
\hline & DHT & Dye & & Amount $(\mu g)$ & Yield (\%) \\
\hline \multicolumn{6}{|c|}{ normal-Dihydrothiamine } \\
\hline $2,6-\mathrm{D}$ & $\begin{array}{c}4 \times 10^{-5 a} \\
, " \\
", \\
",\end{array}$ & $\begin{array}{c}4 \times 10^{-5} \\
", \\
8 \times 10^{-5} \\
4 \times 10^{-4}\end{array}$ & $\begin{array}{l}5.0 \\
6.0 \\
7.0 \\
5.0 \\
5.0\end{array}$ & $\begin{array}{r}22.66 \\
6.01 \\
4.84 \\
24.10 \\
23.62\end{array}$ & $\begin{array}{r}42.6 \\
11.3 \\
9.1 \\
45.3 \\
44.4\end{array}$ \\
\hline $\mathrm{Mb}$ & ", & $\begin{array}{c}4 \times 10^{-5} \\
,\end{array}$ & $\begin{array}{l}2.2 \\
5.0\end{array}$ & $\begin{array}{l}0.53 \\
0\end{array}$ & $\begin{array}{l}1.0 \\
0\end{array}$ \\
\hline $\mathrm{Tb}$ & $\begin{array}{l}\text { ", } \\
\text { ", }\end{array}$ & $4 \times 10^{-4}$ & $\begin{array}{l}2.2 \\
4.0 \\
2.2\end{array}$ & $\begin{array}{r}14.36 \\
3.19 \\
14.63\end{array}$ & $\begin{array}{r}27.0 \\
6.0 \\
27.5\end{array}$ \\
\hline \multicolumn{6}{|c|}{ pseudo-Dihydrothiamine } \\
\hline $2,6-\mathrm{D}$ & $\begin{array}{l}\text { ", } \\
", \\
",\end{array}$ & $\begin{array}{c}4 \times 10^{-5} \\
" \prime \\
8 \times 10^{-5} \\
4 \times 10^{-4}\end{array}$ & $\begin{array}{l}5.0 \\
6.0 \\
7.0 \\
5.0 \\
5.0\end{array}$ & $\begin{array}{c}26.01 \\
7.13 \\
5.69 \\
25.54 \\
26.3\end{array}$ & $\begin{array}{l}48.9 \\
13.4 \\
10.7 \\
48.0 \\
49.5\end{array}$ \\
\hline $\mathrm{Mb}$ & ", & $\begin{array}{c}4 \times 10^{-5} \\
, "\end{array}$ & $\begin{array}{l}2.2 \\
5.0\end{array}$ & $\begin{array}{l}1.06 \\
0\end{array}$ & $\begin{array}{l}2.0 \\
0\end{array}$ \\
\hline $\mathrm{Tb}$ & ", & $4 \times{ }^{\prime \prime}$ & $\begin{array}{l}2.2 \\
4.0 \\
2.2\end{array}$ & $\begin{array}{r}18.35 \\
5.05 \\
18.62\end{array}$ & $\begin{array}{r}34.5 \\
9.5 \\
35.0\end{array}$ \\
\hline
\end{tabular}

a Corresponds to $53.2 \mu \mathrm{g}$.

The condition was the same as that described in Table I, excluding the incubation for $600 \mathrm{~min}$.

TABLE III

Aerobic Oxidation of Dihydrothiamine in Acidic Solution

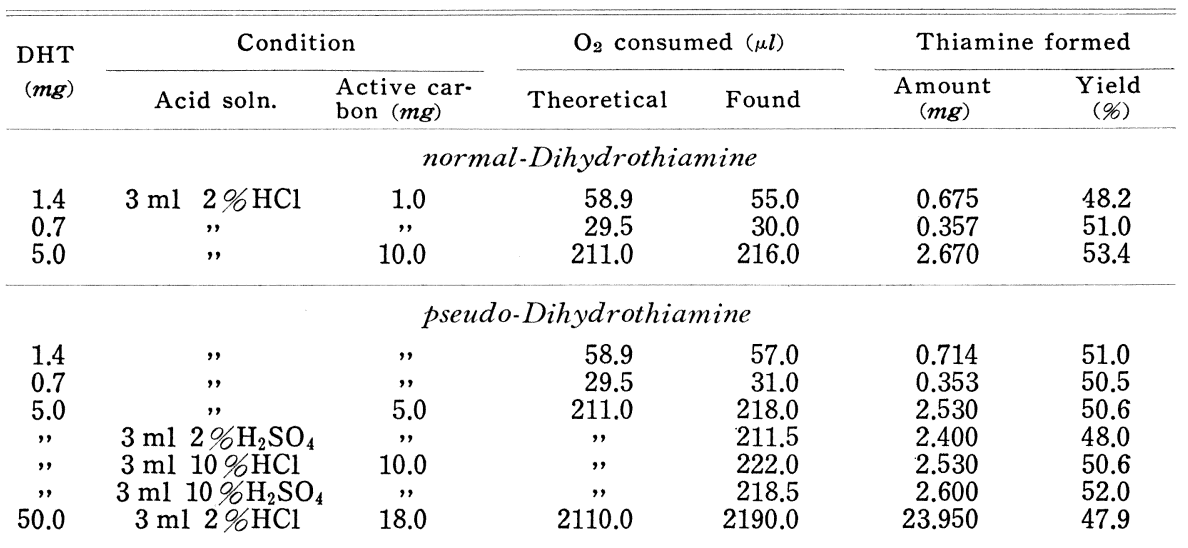

When thiamine-HCl was treated under the same condition as DHT as indicated above, the recovery of thiamine- $\mathrm{HCl}$ was between 99 and $103 \%$. No oxygen consumption was detected. 
After completion of consumption, the thiamine produced was estimated. The yield of the vitamin was nearly 50 per cent as shown in Table III. ${ }^{3}$

\section{The Oxidation by Organic and Inorganic Oxidants}

The oxidizing reagents were selected considering the high redox-potential of DHT. The inorganic oxidants having $E_{0}+0.167$ to $+1.300 \mathrm{~V}$ were allowed to react with DHT in $0.3 \mathrm{~N} \mathrm{HCl}$ or in a buffer solution of $\mathrm{pH} 5.0$ in Thunberg tube. Quinones were used as organic oxidants. But quinones of uniform chemical structure could not be obtained except for $p$-quinone. Therfore, quinone solutions were prepared in buffer solution ( $\mathrm{pH} 7.0$ ) by exposing to air, and the oxidation of DHT was coupled to quinone formation at the same time. The results were shown in Table IV. Among the oxidations of DHT by inorganic oxidants, production of thiamine by $\mathrm{Cu}^{2+}$ (having a low redox-potential) showed a rather high value, and it may not be a simple potentiometric oxidation.

TABLE IV

Formation of Thiamine by Inorganic Oxidants

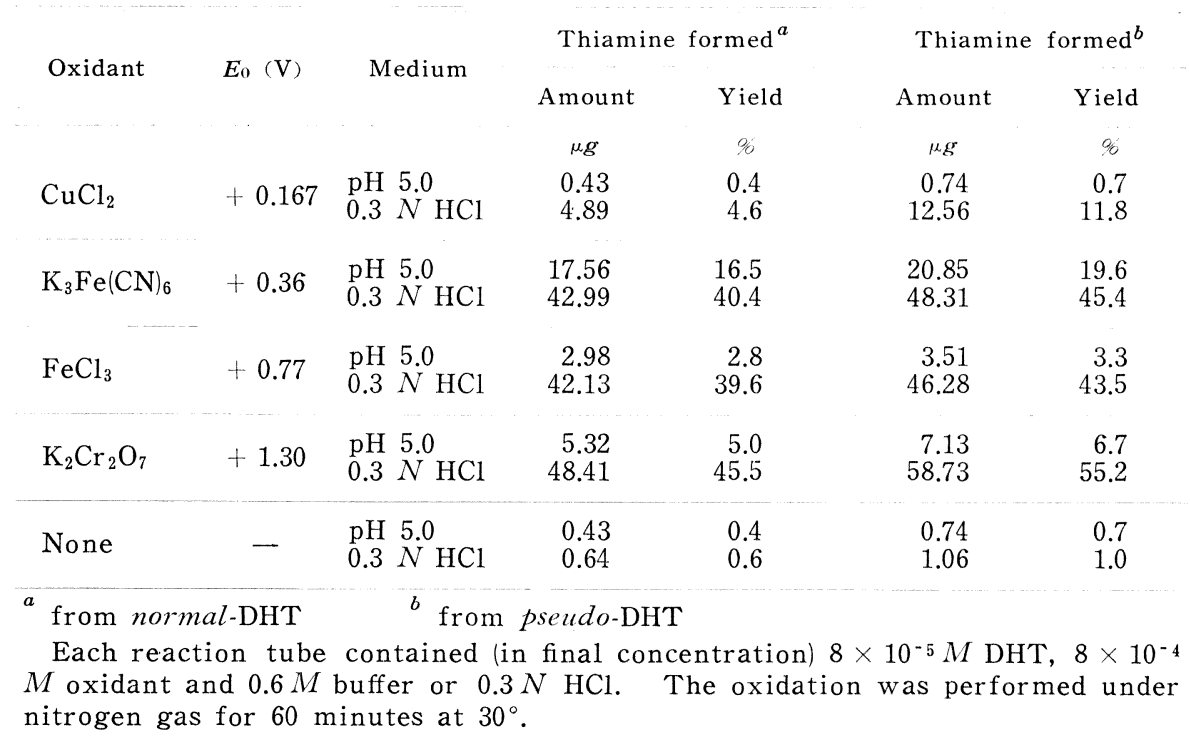

Another reagents such as arsenic acid, mercuric nitrate, potassium iodate and potassium permanganate were used, but the production of thiamine failed to be recognized, probably due to complex formation of DH'T or of the thiamine produced with the oxidants, or due to further oxidative degradation.

In the cases of organic oxidants, appreciable amount of thiamine was produced under physiological conditions (at $\mathrm{pH}$ 6.0), as shown in Table V. When

3 In Hirano's report (4) the absolute yield of thiamine was not given. According to his latest reexamination carried out under the same condition, the absolute yield of thiamine was 48.8 per cent (private communication). 
TABLE V

Formation of Thiamine by Organic Oxidants

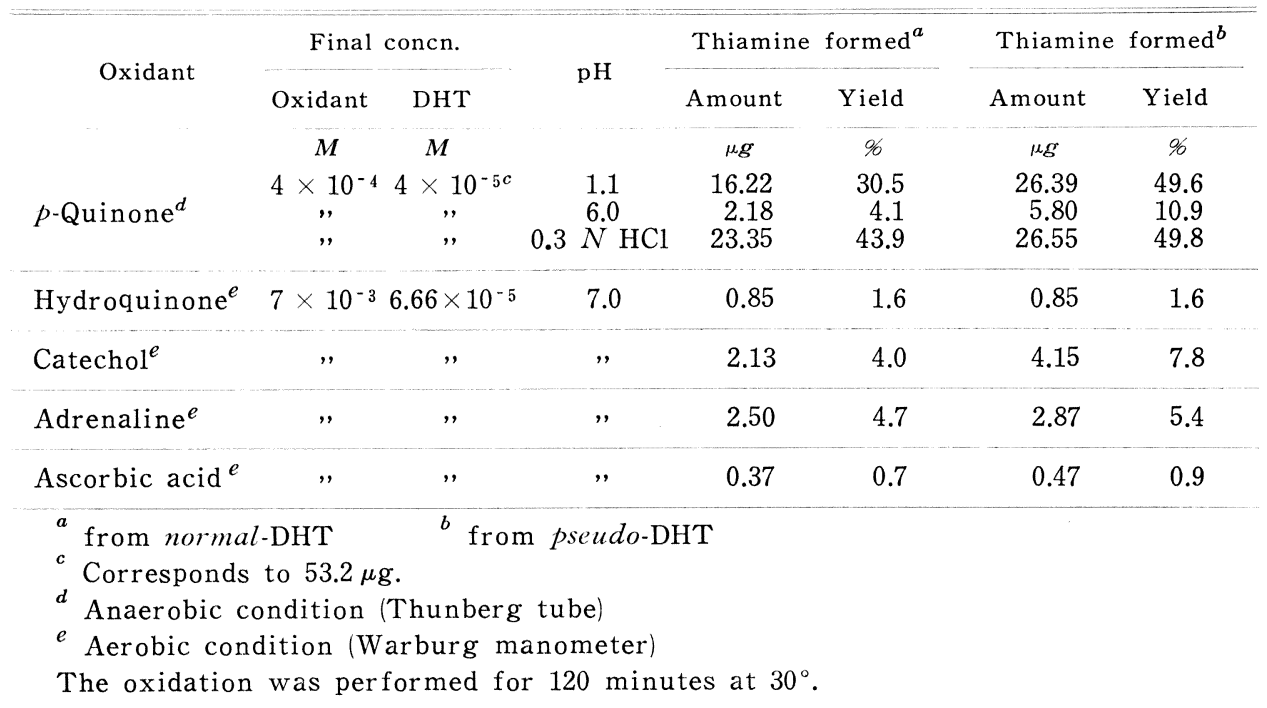

the experiments were carried out under a similar condition at $\mathrm{pH} 1.0$, the yield of thiamine was nearly 50 per cent. As the redox-potential of ascorbic acid is obviously low, the production of thiamine was negligible as compared to the control.

\section{DISCUSSION}

DHT was oxidized by participation of $\left[\mathrm{H}^{+}\right]$in the presence of potentially oxidizable oxidants resulting in the production of thiamine. Therefore, it has been known that DHT in acidic solution was unstable when exposed to air. It has some resemblance to the stability of $\mathrm{DPNH}$ and $\mathrm{DPN}^{+}$in acidic and alkaline solutions. The maximum yield of thiamine was nearly 50 per cent when DHT was oxidized to thiamine as shown in Tables II to IV. On the other hand, half of DHT is degraded, probably hydrolytically, to unknown substances. This inference is based on a hydrogen sulfide-like smell when the oxidation was effected with active carbon.

Since the yield of thiamine was about 50 per cent, the DHT solution dissolved in distilled water was always used in this experiment. If the DHT solution dissolved in $0.01 \mathrm{~N} \mathrm{NaOH}$ was oxidized by ferric chloride under the same condition, the yield of thiamine was not constant.

The difference between the oxidations of the two isomers, normal-and pseudo-DHT, was hardly recognized, as show'n in Table III. But the rate of

\footnotetext{
${ }^{4}$ Recently, they were identified by Matsukawa and Yurugi (9) to be tris-[2-methyl-4aminopyrimidyl-(5)] methyl-trimethylene-triamine, 2-methyl-4-amino-5-aminomethylprimidine, and $\gamma$-aceto- $\gamma$-mercaptopropyl alcohol.
} 
thiamine production from pseudo-DHT was somewhat faster than the other as given in Table II and IV. These findings resembled those obtained by Kawasaki and Okada (10), possibly related to the isomeric structures of these substances. If DHT is oxidized in plant tissues, it does not seem to be oxidized by metallic ions, because the inorganic oxidants can act only in higher hydrogen ion concentrations. It is probable that the oxidation of DHT is coupled with the enzymes of polyphenol oxidizing system. Appreciable amounts of thiamine was produced from DHT by adding the oxidized form of adrenaline, suggesting a possible role of DHT in animal tissues.

\section{SUMMARY}

1. normal- and pseudo-Dihydrothiamine were oxidized by various organic and inorganic oxidants having high redox-potential.

2. normal- and pseudo-Dihydrothiamine were oxidized by the dyes having the redox potentials higher than $+0.40,+0.36$, and $+0.23 \mathrm{~V}$ at $\mathrm{pH} 2.2,5.0$, and 7.0 respectively.

3. The absolute yield of thiamine produced by the oxidation of dihydrothiamine was about 50 per cent under the experimental conditions described in this paper.

\section{ACKNOWLEDGMENT}

We wish to express sincere thanks to Drs. T. Matsukawa, H. Hirano, S. Yurugi, and H. Yonemoto of the Research Laboratories of Takeda Pharmaceutical Industries Ltd., Osaka, for kind suggestions and the precious gift of dihydrothiamine.

\section{REFERENCES}

1. Karrer, P., and Krishna, H., Helv. Chim. Acta. 33, 555 (1950).

2. Karrer, P., and Krishna, H., ibid. 35, 459 (1952).

3. Iwatsu, T., J. Pharm. Soc. Japan 75, 677 (1955).

4. Hirano, H., Yonemoto, H., and Hara, Y., Pharm. Bull. Japan 7, 545 (1959).

5. Matsukawa, T., and Iwatsu, T., The 76 th Meetings of the Vitamin B Research Committee of Japan, January 22 (1955).

6. Schopfer, W.H., Bein, M. L., and Besson, G., Z. Vitaminforsch. 23, 36 (1951).

7. Fujiwara, M., and Matsui, K., Anal. Chem. 25, 810 (1953).

8. Asahi, Y., J. Pharm. Soc. Japan 80, 1097 (1960).

9. Matsukawa, T., and Yurugi, S., The 122 th Meetings of the Vitamin B Research Committee of Japan, October 15 (1960).

10. Kawasaki, C., and Okada, K., Vitamins 16, 61 (1959). 